\title{
Applying Protection Motivation Theory to Understand Generation Z Students Intention to Comply with Educational Software Anti Piracy Law
}

\author{
https://doi.org/10.3991/ijet.v14i18.10973 \\ Bobby Ardiansyah Miraja ${ }^{(凶)}$, Satria Fadil Persada \\ Institut Teknologi Sepuluh Nopember (ITS), Surabaya, Indonesia \\ bobard.m@outlook.com \\ Yogi Tri Prasetyo \\ Mapua University, Manila, Philippines \\ Prawira Fajarindra Belgiawan \\ Institut Teknologi Bandung, Bandung, Indonesia
}

A.A.N Perwira Redi

Universitas Pertamina, Jakarta, Indonesia

\begin{abstract}
Software piracy has numerous negative effects. The concern of software piracy is not limited to software developers but also educational institutions. The purpose of the current study was to investigate the factors contributing to the behavioral intention of Generation Z students' to comply with educational software anti-piracy laws by utilizing the Protection Motivation Theory (PMT). The results indicated that self-efficacy and response efficacy had significant relationships with the behavioral intention of Generation Z's intention to comply with educational software anti-piracy laws. Several insights from practical and managerial perspective were also discussed. In the end, software developer and academic institutions could use this model to promote anti-piracy behavior in the future.
\end{abstract}

Keywords-Educational Software, Protection Motivation Theory, Generation Z, Software Piracy, Behavioral Intention

\section{Introduction}

Information and Communication Technology (ICT) and its use as a part of the educational process is a never-ending global initiative. Many traditional educational challenges, such as inclusion, equity, and quality, could be tackled by the presence of ICT in educational settings. In fact, ICT is seen as an essential aspect to achieve the Sustainable Development Goals 4 which is "Ensure inclusive and equitable quality education and promote lifelong learning opportunities for all" by 2030 [1]. Although there are many examples of the success story of using ICT to enhance the educational pro- 
cess [2], some challenges still exist. One of the remaining challenges today is software piracy.

Software piracy was defined as the unauthorized use or duplication of software; in some sense, software piracy is essentially a theft [3]. A recent report stated that pirated software accounts for $34 \%$ of global software use [4]. The education sector is partly responsible for this piracy problem; a study states that college students are the individuals that are most prone to pirate software [5]. This concerns not only software provider who experiences substantial sales loss, but also educational institute, which will also suffer indirect impacts, whether it is economical or an ethical one. Some example of the negative consequences of software piracy is financial loss, computer viruses, and spyware. The figure for financial loss reaches almost $73 \$$ billion in US dollars, and the possibility of getting exposed to malicious codes when using pirated software is more than $50 \%$ [6]. Therefore, it is necessary to understand the student's behavior towards the compliance of pirated software, particularly for prevention scenarios by the educational institute and software developers.

The purpose of the current study was to investigate the factors contributing to the behavioral intention of Generation $\mathrm{Z}$ students' to comply with educational software anti-piracy laws. We utilized a framework called the Protection Motivation Theory (PMT) to derive the factors affecting students' decision to laws regarding authorized use of educational software. Generation $\mathrm{Z}$ is a very important generation. Therefore, understanding Generation $Z$ students can also be seen as the equivalent of understanding the majority of today's students and the future of modern society [7].

The PMT can interpret how individuals respond to fear appeals; this includes threats or dangerous behaviors. PMT systematically categorizes factors of how individuals perceive threats; these factors are 1 . Rewards or benefits: motivations to push individuals to increase or keep on doing undesirable behavior; 2 . Severity: the extent of threats' consequences; and 3. Vulnerability: the susceptibility of individuals to a particular threat [8]. The rewards and benefits aspect of PMT's threats perception categorization is also understood as coping behavior: the perceived self-efficacy of an individual and the response efficacy [9]. This study utilized PMT as the theoretical framework for determining students' threat and coping appraisal of their compliance towards anti-piracy laws. This study contributes to the understanding of college students to comply with the educational software anti-piracy laws; determined by their threat and coping appraisals.

This rest of this study is organized as follows. Section 2 presents the literature review. Section 3 discusses the methodology, instrument development, and analysis tools are the main topics for the section. Section 4 presents the results and insights from the data gathered will be offered after conducting statistical analysis. Finally, the concluding remark, as well as the limitation and suggestion for future research, are given in Section 5 . 


\section{$2 \quad$ Literature Review}

\subsection{Generation $\mathrm{Z}$ students}

Generation $\mathrm{Z}$ students are the students born after the year 1995. Loyal, thoughtful, and open-minded are some of their most known attributes as individuals; they seek to be an agent of change and a firm believer of the concept of 'making a difference' [10]. Generation $\mathrm{Z}$ is seen as the most technology-adept generation; they are accustomed to technologies that are new and has futuristic mindset [11]. Previous research discussed the generational factor on piracy. Specifically Stanley assessed the Millennials and their music piracy, showed that this generation pirate music more. In addition, another research showed that generation had its importance in understanding Intellectual Property Right infringement behavior [12]. The current study used Generation $\mathrm{Z}$ as a subject since they could be more potential in utilizing technologies, and in turn, could use this potential to do negative behavior such as doing educational software piracy more. The results of this study could be used as consideration for a future decision regarding specific actions to reduce educational software piracy.

\subsection{Educational software piracy}

This study sees software piracy not in the general sense but rather in the more specific context that is educational; involving the pirated use of a software that is used for academic purpose. Thus, educational software piracy is defined as the unauthorized used of software(s) for educational uses; these software are not limited by platform, web-based or desktop-based software for educational uses [13, 14] are still considered as subjects for the present research' definition. Software piracy in an educational setting is seen as a more concerning problem compared to software piracy in business settings, possibly because the different approach done by academic officials which is less forceful than compared to business communities approach [15]. Users of pirated educational software face the same penalties as non-educational software pirate: legal consequences. Not only that, it is known that software piracy or the attack on Intellectual Property Right affects economic development and prosperity of a country [16] and aside from these obvious, measurable consequences, there is also the moral aspect, even if it is different for each individual [17]. This study utilized the opposing aspect of piracy, as explained in the first section: the behavioral intention of a student's compliance towards the anti-piracy laws of educational software.

\subsection{Software anti-piracy laws}

The Anti-Piracy laws hold differently in different countries; one standard reference for anti-piracy law is from the United States. The US 1980 copyright act defines software as a set of codes used to run some instructions with particular purposes and the copyright law in the US protects software except the software being placed in the public domain $[18,19]$. Other than in the US, it is known that countries with similar 
legal origin also possesses similar law regarding software piracy or more broadly, Intellectual Property Rights (IPR). Common law countries are seen to have better IPR protection laws compared to civil law countries. Common law countries consisted of countries such as Zambia, Nigeria, United States, and Malaysia and civil law countries consisted of countries such as Algeria, Morocco, and Egypt [16]. Aside from these minor differences, all laws related to software piracy are all similar and dictates that software piracy is illegal.

\subsection{The protection motivation theory}

The PMT is based on the Theory of Reasoned Action (TRA); its primary use is to find out an individual's reason for why they take a particular protective behavior [20, 21]. The PMT proposes that information of threats can trigger an individual's cognitive mediating process; that information of threats can trigger an individual's cognitive mediating process; this process is creating two possible outcomes that are the adaptive or maladaptive response. There are two items that are proposed by the PMT model that can explain protective behavior: threat appraisals and coping appraisals. Vulnerability and risks' susceptibility is the primary determinant for threat appraisals. In the other hand, the coping aspect of doing something, represented by self-efficacy, response cost, and response efficacy is used to be the determinant of coping appraisals [22]. When the threat appraisal factors are provoked, a maladaptive response such as the non-compliance with software anti-piracy laws could appear and conversely, when coping appraisals factors is provoked, an adaptive response such as the compliance towards software anti-piracy laws will emerge [8]. Each of the determinants stated previously is used to construct the hypotheses for this study.

Perceived Vulnerability was the measurement used in the first hypothesis, it is an assessment to determine the scale of a threat's exposure done by an individual [20]. For this study, the exposure would be the possibilities of getting exposed to the consequences of using illegal educational software. Thus, the first hypothesis was:

H1: Perceived Vulnerability had a positive effect on Generation Z students' Behavior Intention to use of legal educational software

Perceived severity is also known as the magnitude of a penalty for harmful behavior [23]. It also is defined as the degree of negative consequences or harm linked with a particular threat. For this study, the negative consequences would be the consequences of using illegal educational software such as the risk of being infected by computer viruses, the legal penalty, and the moral consequences. Thus, the second hypothesis was:

H2: Perceived severity had a positive effect on Generation $Z$ students' Behavior Intention to use of legal educational software

The next variable is Response Efficacy; it is a part of the coping appraisal factors which means that Response Efficacy could affect student's compliance positively. Response Efficacy is defined as the beliefs that recommended coping responses could be effective in reducing a particular threat [24]. In this study, Response Efficacy was used to examines the degree of Generation Z student's beliefs that compliance to- 
wards software anti-piracy laws could effectively reduce software piracy negative consequences. Thus, the next hypothesis was:

H3: Response Efficacy had a positive effect on Generation Z students' Behavior Intention to use of legal educational software

Self-efficacy is defined as one's strength in doing a particular action to generate a particular result [25]. Self-efficacy is also known to have relationships to academic performance and motivation, and using this concept, performance, and motivation to comply with software piracy-law is hypothesized to have a positive effect from Generation $\mathrm{Z}$ self-efficacy in complying to software anti-piracy laws [26]. Thus, the fourth hypothesis was:

H4: Self-efficacy had a positive effect on Generation Z students' Behavior Intention to use of legal educational software

Lastly, the Response Cost is understood as the costs that have a direct relation with taking adaptive action or in this case, compliance with software anti-piracy laws. Many previous studies found that there was a significant negative relationship between response costs and adaptive behavior [27]. Thus, the last hypothesis was:

H5: Perceived vulnerability had a negative effect on Generation $Z$ students' Behavior Intention to use of legal educational software

These five hypotheses were the foundation for this research, the visualized model can be seen in Fig. 1

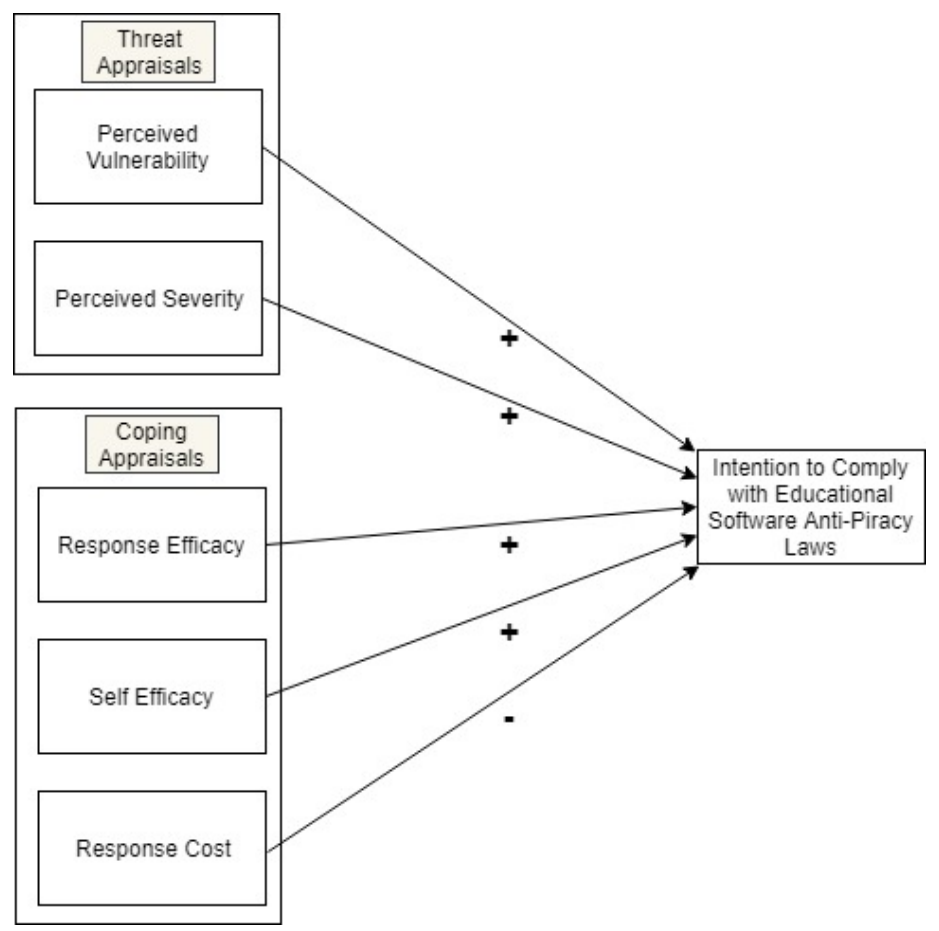

Fig. 1. The Proposed Model 


\section{$3 \quad$ Research Methodology}

\subsection{Respondents}

The data for the present research was gathered using the questionnaire The respondents for the questionnaire were Generation $\mathrm{Z}$ defined in the literature review section, spread across many different provinces and cities in Indonesia. The total of 167 respondents, in which the majority resides in Western Indonesian Time region (UTC+7), the most populous time zone in Indonesia, the rest of the respondents resides in Central Indonesian Time region (UTC+8), the second most populous time zone in Indonesia. Respondents were affiliated with different institutions in Indonesia, ranging from some of the most prominent public higher education institutions to private higher education institutions. $46.1 \%$ of the respondents were male and $51.5 \%$ were female, the rest $2.4 \%$ preferred not to answer. The respondents' birth year is shown in Fig.2. The sampling method used to collect the data from the respondents was the purposive sampling method, a form of non-probability sampling.

\section{Birth year \\ Average: 1998.55}

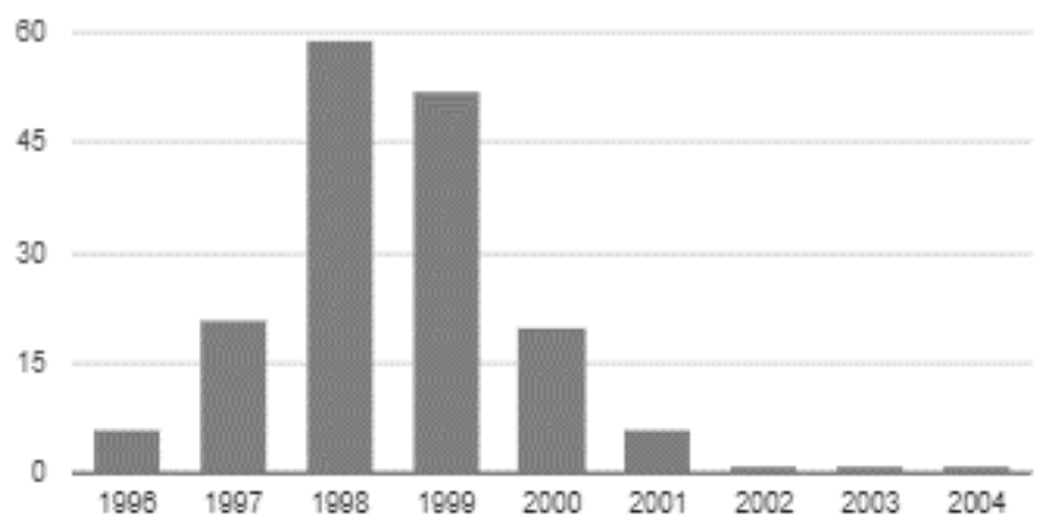

Fig. 2. Respondents' Birth Year

\subsection{Questionnaire design}

We designed our questionnaire to measure different kinds of threat and coping appraisals variables. In order to extract these variables, a set of questionnaire items for each variable was utilized. Three to five questionnaire items were used to project a particular variable/factor, Likert scale (five-point), ranging from 1, which represents "Strongly Agree" to 5, which represents "Strongly Disagree." The questionnaire instrument was divided into two separate sections: demographics and measurements. Demographics section's explanation takes place in the 3.1 and 4.1 sub-section of this 
research article. The measurement section questions the six variables as a part of PMT model projected with the total of 22 questionnaire items; items were constructed by using references from past researches and own modifications [8, 28, 29]. The list of measurement questionnaire items is shown in table 1.

Table 1. Questionnaire Items

\begin{tabular}{|c|c|}
\hline Construct & Item \\
\hline \multirow{4}{*}{$\begin{array}{l}\text { Perceived vulnerabil- } \\
\text { ity }\end{array}$} & PV1: If I used illegal educational software, I could get computer viruses \\
\hline & $P V 2$ : If I used illegal educational software, I am vulnerable to legal consequences \\
\hline & $\begin{array}{l}P V 3: \text { I believe if I comply with educational software anti-piracy law, negative conse- } \\
\text { quences for me and my campus will be decreased }\end{array}$ \\
\hline & $\begin{array}{l}\text { PV4: As a student, I believe there are significant risks in using illegal educational } \\
\text { software }\end{array}$ \\
\hline \multirow{4}{*}{ Perceived severity } & $\begin{array}{l}\text { PS1: I believe that complying with educational software anti-piracy laws is very } \\
\text { important }\end{array}$ \\
\hline & PS2: It is dangerous for me to use illegal educational software \\
\hline & PS3: The negative consequences of using illegal educational software is fatal \\
\hline & PS4: I see the use of illegal educational software as a dangerous thing \\
\hline \multirow{4}{*}{ Response efficacy } & $\begin{array}{l}\text { RE1: Complying with educational software anti-piracy laws is an effective way to } \\
\text { avoid computer viruses }\end{array}$ \\
\hline & $\begin{array}{l}\text { RE2: Complying with educational software anti-piracy laws is an effective way to } \\
\text { avoid legal consequences }\end{array}$ \\
\hline & $\begin{array}{l}\text { RE3: Complying with educational software anti-piracy laws is the right thing to do in } \\
\text { the educational settings }\end{array}$ \\
\hline & $\begin{array}{l}\text { RE4: My educational environment is better if I comply with educational software } \\
\text { anti-piracy laws }\end{array}$ \\
\hline \multirow{4}{*}{ Self efficacy } & SE1: I am capable of complying with educational software anti-piracy laws \\
\hline & $\begin{array}{l}\text { SE2: I am capable of complying with educational software anti-piracy laws without } \\
\text { the help of others }\end{array}$ \\
\hline & $\begin{array}{l}\text { SE3: Complying to educational software anti-piracy laws is an easy thing for me to } \\
\text { do }\end{array}$ \\
\hline & $\begin{array}{l}\text { SE4: Without people forcing me, I am capable of complying with educational soft- } \\
\text { ware anti-piracy laws }\end{array}$ \\
\hline \multirow{5}{*}{ Response cost } & $\begin{array}{l}R C 1 \text { : Too many inconveniences for me to comply with educational software anti- } \\
\text { piracy laws }\end{array}$ \\
\hline & $R C 2$ : Complying with educational software anti-piracy laws is a waste of time \\
\hline & $\begin{array}{l}R C 3: \text { The cost I exerted is too high compared to complying with educational soft- } \\
\text { ware anti-piracy laws }\end{array}$ \\
\hline & $\begin{array}{l}R C 4: \text { Aside from the waste of time, complying with educational software anti-piracy } \\
\text { laws also waste other resources }\end{array}$ \\
\hline & $R C 5$ : It is not worth it to comply with educational software anti-piracy laws \\
\hline \multirow{5}{*}{$\begin{array}{l}\text { Intention to comply } \\
\text { with educational } \\
\text { software anti-piracy } \\
\text { laws }\end{array}$} & $\begin{array}{l}\text { BI1: I believe that complying with educational software anti-piracy laws is very } \\
\text { important }\end{array}$ \\
\hline & BI2: It is dangerous for me to use illegal educational software \\
\hline & BI3: The negative consequences of using illegal educational software is fatal \\
\hline & BI4: The negative consequences of using illegal educational software is fatal \\
\hline & BI5: I see the use of illegal educational software as a dangerous thing \\
\hline
\end{tabular}

\subsection{Data processing}

Data were gathered by using an online questionnaire means, using Google Forms by Google to distribute the questionnaire. The 167 data were collected in the span of 
two months, starting from March $15^{\text {th, }} 2019$ to May $15^{\text {th }}, 2019$. Structural Equation Modelling (SEM) approach was utilized to analyze the data. The five hypotheses were evaluated using the software. Furthermore, several tests were done to check the validity of the analysis. Data test to check the reliability and the convergent validity of the data will be conducted in the first place before doing a model test. The model test was utilized to test the appropriateness of the model. The Cronbach Alpha was used to measure the internal consistency of a data set, using a standard minimum of 0.7 . Composite Reliability and Average Variance Extracted on the other hand, was used to test the convergent validity of the model, both having the minimum threshold of 0.7 and 0.5 , respectively [30]. The model fit test uses several tests such as the Goodness of Fit Index and Tucker-Lewis Index, for the present research we used five different model tests: GFI, NFI, IFI, TLI, and CFI.

\section{$4 \quad$ Result and Analysis}

\subsection{Descriptive statistics}

To gain a more profound insight, we asked questions in addition to instrument measurement questions; these questions consisted of three items related to educational software piracy in their experience. The first question of "Have you ever used illegal educational software?" revealed that the majority of respondents had used illegal educational software, with 44.3\% answered "Yes" 26.9\% answered "Maybe" and $28.7 \%$ answered "No". "Maybe" was showing a more significant percentage than "No", there were two possibilities in explaining this number: first being respondents' who answered "Maybe" did not fully understand whether or not their educational software was licensed or not (this is possible because of the high digital divide in Indonesia [31]), and the second being the respondents had used illegal educational software and are afraid/ashamed, to tell the truth. The second question asked whether or not the respondents understand the legal consequences of pirating educational software; 89.2\% answered "Yes", indicating that the majority of the respondent which answer "Yes" for the first question pirates illegal educational software consciously. The third question asked the respondents' perception of the most important educational software category; result revealed that the majority of the respondents $(66.5 \%)$ answered office-related software (Word Processing, Presentation, and Spreadsheet), the second most important $(21.6 \%)$ educational software category for our respondents were specific software for different technical usage (SPSS, Matlab, Minitab, AutoCAD), other than these top two categories, multimedia software (After Effects, Sony Vegas, Photoshop) dominate the remaining respondent perception of the most important educational software category.

\subsection{Data analysis}

This subsection continue the previously mentioned reliability and model fit test including the answer to the previously proposed hypotheses. For the reliability and 
convergent validity tests, all items were higher the minimum standard set in the 3.3 subsections except PV2, though it was still considered as a moderately good factor loading by some source [32]. The total result for each item and constructs are provided in table 2.

Table 2. Data fit tests

\begin{tabular}{|c|c|c|c|c|c|}
\hline Construct & Item & Factor loadings & $\begin{array}{c}\text { Cronbach's } \\
\alpha\end{array}$ & $\begin{array}{l}\text { Composite } \\
\text { reliability }\end{array}$ & Ave \\
\hline \multirow{3}{*}{ Perceived vulnerability } & PV2 & 0.566 & \multirow{3}{*}{0.728} & \multirow{3}{*}{0.74} & \multirow{3}{*}{0.50} \\
\hline & PV3 & 0.622 & & & \\
\hline & PV4 & 0.891 & & & \\
\hline \multirow{3}{*}{ Perceived severity } & PS2 & 0.709 & \multirow{3}{*}{0.822} & \multirow{3}{*}{0.82} & \multirow{3}{*}{0.62} \\
\hline & PS3 & 0.913 & & & \\
\hline & PS4 & 0.729 & & & \\
\hline \multirow{3}{*}{ Response efficacy } & RE2 & 0.724 & \multirow{3}{*}{0.834} & \multirow{3}{*}{0.84} & \multirow{3}{*}{0.63} \\
\hline & RE3 & 0.856 & & & \\
\hline & RE4 & 0.801 & & & \\
\hline \multirow{4}{*}{ Self efficacy } & SE1 & 0.809 & \multirow{4}{*}{0.917} & \multirow{4}{*}{0.92} & \multirow{4}{*}{0.74} \\
\hline & SE2 & 0.879 & & & \\
\hline & SE3 & 0.857 & & & \\
\hline & SE4 & 0.886 & & & \\
\hline \multirow{4}{*}{ Response cost } & $\mathrm{RC} 2$ & 0.79 & \multirow{4}{*}{0.874} & \multirow{4}{*}{0.88} & \multirow{4}{*}{0.64} \\
\hline & $\mathrm{RC} 3$ & 0.774 & & & \\
\hline & $\mathrm{RC} 4$ & 0.88 & & & \\
\hline & RC5 & 0.746 & & & \\
\hline \multirow{5}{*}{$\begin{array}{l}\text { Intention to comply with educa- } \\
\text { tional software anti-piracy laws }\end{array}$} & BI1 & 0.786 & \multirow{5}{*}{0.914} & \multirow{4}{*}{0.89} & \multirow{4}{*}{0.62} \\
\hline & $B I 2$ & 0.843 & & & \\
\hline & $B I 3$ & 0.823 & & & \\
\hline & BI4 & 0.759 & & & \\
\hline & BI5 & 0.707 & & & \\
\hline
\end{tabular}

Note: Items that have factor loading below 0.5 (PV1, PS1, RE1, RC1) was removed, and model respecification was then conducted

A different kind of indicators in Structural Equation Modeling was tested. A particular model fit tests parameter in which showed a good value was used as the basis of the model fit test. The Comparative Fit Index (CFI) showed an acceptable value of 0.81 (the acceptable minimum value being 0.8) [33,34]. Following the tests, our hypotheses were then tested. Analyzing the estimated direct correlation for each hypothesis and its significance, it yielded a result summarized in Table 3.

The significance values in Table 3 is calculated by utilizing a bootstrap technique. A thousand dummy samples were used for the bootstrap (using maximum likelihood parameters) because our data was less than 400 data. The dummy samples were then compared to the real data, generating the significance value. We used 95 as the biascorrected confidence interval. This mean of generating significance value is recommended by many past types of research [35-39]. 
Table 3. Hypotheses Evaluation

\begin{tabular}{|l|c|c|l|}
\hline $\begin{array}{c}\text { Correlation between } \\
\text { factors }\end{array}$ & Estimates $(\boldsymbol{\beta})$ & Significance $(\mathbf{p}<\mathbf{0 . 0 1 )}$ & \multicolumn{1}{|c|}{ Hypothesis } \\
\hline $\mathrm{PV} \rightarrow \mathrm{BI}$ & .022 & .820 & Not supported \\
\hline $\mathrm{PS} \rightarrow \mathrm{BI}$ & -.016 & .850 & Not supported \\
\hline $\mathrm{RE} \rightarrow \mathrm{BI}$ & .447 & .003 & Supported \\
\hline $\mathrm{SE} \rightarrow \mathrm{BI}$ & .721 & .002 & Supported \\
\hline $\mathrm{RC} \rightarrow \mathrm{BI}$ & .001 & .907 & Not supported \\
\hline
\end{tabular}

There were only two hypotheses that show positive effects: Response Efficacy and Self Efficacy; having a value of 0.447 and 0.721. Using Squared Multiple Correlation, it can be interpreted that $72.1 \%$ of the Generation Z students' intention to comply with legal educational software was able to be described by this structural model. The remaining $27.9 \%$ could probably be explained by factors outside the Protection Motivation Theory structural model. This value is comparable to past successful researches utilizing structural equation modelling [40-42].

\subsection{Managerial interpretation}

With the high Squared Multiple Correlation value, the Protection Motivation Theory can be seen as an appropriate model used to determine the appraisal of rules compliance. This was the first managerial interpretation from this research; future researches trying to understand compliance could utilize the PMT to gain a more comprehensive insight. The next interpretation would be from the result of direct correlation estimates summarized in Table 3. Two variables: Response Efficacy and Self Efficacy have relatively high estimates in predicting the Generation $Z$ students' intention to comply with legal educational software laws, since both variables came from the Coping Appraisal aspect of the PMT, it can also be understood that the threat appraisal factors is not considered greatly by Generation Z' student on their intention to comply with legal educational software. Generation $Z$ however, considers greatly the Self Efficacy aspect, the belief that one's could follow the laws of educational software anti-piracy laws. Institutions and software developer could use this fact to promote more how to comply with the software anti-piracy laws, giving the Generation $\mathrm{Z}$ students an understanding that complying is the right thing and easy to do. The second most important variable is the Response Efficacy, for this case, this is how Generation Z students' perceive the effectiveness of their action of complying to the educational software anti-piracy laws. In line with the previous recommendation, giving more education on how compliance could increase positive effects whether in the context of legal consequences avoidance and computer viruses avoidance or in term of having a better educational environment and doing the morally right action (as represented by item RE3). 


\section{Conclusion}

Software piracy has become a major concern for software developers and also educational institutions. The purpose of the current study was to investigate the factors contributing to the behavioral intention of Generation Z students' to comply with educational software anti-piracy laws by utilizing PMT. Using the Structural Equation Modeling (SEM), we analyzed 167 data from Generation $Z$ respondents and found out that the PMT was a relatively good model to explore Generation Z students intention to comply with educational software anti-piracy laws. The model showed that the two variables that had significant positive effects on the intention to comply with educational software anti-piracy laws were "Response Efficacy" and "Self Efficacy". Emphasizing the previous subsection recommendation, educational institutions and software developer could give Generation Z students' more understanding about how easy it is to comply with educational software anti-piracy laws and its positive impacts. Future research could expand this research further by utilizing the actual use of behavior factors, improving this model by not only understanding the intention to comply but also the actual compliance.

\section{References}

[1] UNESCO. (2018). Positioning ICT in Education to Achieve the Education 2030 Agenda in Asia and the Pacific: Recommendations for a Regional Strategy. Available: https://teams.unesco.org/ORG/fu/bangkok/public events/Shared\%20Documents/EISD/201 8/Feb-SARSIE/26_Feb_Positioning\%20ICT\%202030.pdf

[2] W. J. Pelgrum and N. Law, ICT in education around the world: Trends, problems and prospects. UNESCO: International Institute for Educational Planning., 2003.

[3] R. M. Siegfried, "Student attitudes on software piracy and related issues of computer ethics," Ethics and Information technology, vol. 6, no. 4, pp. 215-222, 2004. https://doi. org/10.1007/s10676-004-3391-4

[4] M. Das, "Software Piracy," 2019.

[5] G. E. Higgins and D. A. Makin, "Self-control, deviant peers, and software piracy," Psychological reports, vol. 95, no. 3, pp. 921-931, 2004. https://doi.org/10.2466/pr0.95.3.9 $\underline{21-931}$

[6] J. Corwin, "Preventing Pirated Software Use within an Organization," 2018.

[7] S. F. Persada, B. A. Miraja, and R. Nadlifatin, "Understanding the Generation Z Behavior on D-Learning: A Unified Theory of Acceptance and Use of Technology (UTAUT) Approach," International Journal of Emerging Technologies in Learning, vol. 14, no. 5, 2019. https://doi.org/10.3991/ijet.v14i05.9993

[8] A. Vance, M. Siponen, and S. Pahnila, "Motivating IS security compliance: insights from habit and protection motivation theory," Information \& Management, vol. 49, no. 3-4, pp. 190-198, 2012. https://doi.org/10.1016/j.im.2012.04.002

[9] K. Moran, J. Webber, and T. Stanley, "Protection Motivation Theory (PMT), Risk of Drowning, and Water Safety Perceptions of Adult Caregivers/Parents," The Open Sports Sciences Journal, vol. 11, no. 1, 2018. https://doi.org/10.2174/1875399x01811010050

[10] K. A. Mohr, "Understanding Generation Z students to promote a contemporary learning environment," Journal on Empowering Teaching Excellence, vol. 1, no. 1, p. 9, 2017. 
[11] B. Shatto and K. Erwin, "Moving on from millennials: Preparing for generation Z," The Journal of Continuing Education in Nursing, vol. 47, no. 6, pp. 253-254, 2016. https://doi. org/10.3928/00220124-20160518-05

[12] H. L. Stanley, From the right or the left: Generation Y and their views on piracy, copyright, and file sharing. University of South Alabama, 2011.

[13] M. Misut and M. Misutova, "Software Solution Improving Productivity and Quality for Big Volume Students' Group Assessment Process," International Journal of Emerging Technologies in Learning (iJET), vol. 12, no. 04, pp. 175-190, 2017. https://doi.org/10.399 1/ijet.v12i04.6608

[14] R. Obiedat, L. N. Eddeen, O. Harfoushi, A.-H. Montaha, A. Koury, and N. Alassaf, "Effect of blended-learning on academic achievement of students in the University of Jordan," International Journal of Emerging Technologies in Learning (iJET), vol. 9, no. 2, pp. 37-44, 2014. https://doi.org/10.3991/ijet.v9i2.3220

[15] J. H. Im and P. D. Van Epps, "Software piracy and software security in business schools: an ethical perspective," ACM SIGMIS Database: the DATABASE for Advances in Information Systems, vol. 22, no. 3, pp. 15-22, 1991. https://doi.org/10.1145/126743.1267 47

[16] S. A. Asongu, "Fighting software piracy in Africa: how do legal origins and IPRs protection channels matter?," Journal of the knowledge economy, vol. 6, no. 4, pp. 682-703, 2015. https://doi.org/10.1007/s13132-012-0137-0

[17] N. Park, N. Kang, and H. S. Oh, "Examining intention of digital piracy: an integration of social norms and ethical ideologies," Journal of Information, Communication and Ethics in Society, vol. 16, no. 2, pp. 157-172, 2018. https://doi.org/10.1108/jices-11-2016-0043

[18] D. W. Straub Jr and R. W. Collins, "Key information liability issues facing managers: Software piracy, proprietary databases, and individual rights to privacy," Mis Quarterly, pp. 143-156, 1990. https://doi.org/10.2307/248772

[19] T. U. o. I. a. Chicago. (1999). UIC Policy on Software Piracy.

[20] R. W. Rogers, "Cognitive and psychological processes in fear appeals and attitude change: A revised theory of protection motivation," Social psychophysiology: A sourcebook, pp. 153-176, 1983.

[21] R. W. Rogers, "A protection motivation theory of fear appeals and attitude change1," The journal of psychology, vol. 91, no. 1, pp. 93-114, 1975. https://doi.org/10.1080/00223980. 1975.9915803

[22] H.-y. S. Tsai, M. Jiang, S. Alhabash, R. LaRose, N. J. Rifon, and S. R. Cotten, "Understanding online safety behaviors: A protection motivation theory perspective," Computers \& Security, vol. 59, pp. 138-150, 2016. https://doi.org/10.1016/j.cose.2016.02. $\underline{009}$

[23] H. G. Grasmick and G. J. Bryjak, "The deterrent effect of perceived severity of punishment," Social forces, vol. 59, no. 2, pp. 471-491, 1980. https://doi.org/10.1093/sf/59. 2.471

[24] S. Milne, P. Sheeran, and S. Orbell, "Prediction and intervention in health-related behavior: A meta-analytic review of protection motivation theory," Journal of Applied Social Psychology, vol. 30, no. 1, pp. 106-143, 2000. https://doi.org/10.1111/j.1559-1816.2 000.tb02308.x

[25] C. Peechapol, J. Na-Songkhla, S. Sujiva, and A. Luangsodsai, "An Exploration of Factors Influencing Self-Efficacy in Online Learning: A Systematic Review," International Journal of Emerging Technologies in Learning (iJET), vol. 13, no. 09, pp. 64-86, 2018. https://doi. org/10.3991/ijet.v13i09.8351 
[26] A. Razzaq, Y. T. Samiha, and M. Anshari, "Smartphone Habits and Behaviors in Supporting Students Self-Efficacy," International Journal of Emerging Technologies in Learning, vol. 13, no. 2, 2018. https://doi.org/10.3991/ijet.v13i02.7685

[27] Y. Lee, "Understanding anti-plagiarism software adoption: An extended protection motivation theory perspective," Decision Support Systems, vol. 50, no. 2, pp. 361-369, 2011. https://doi.org/10.1016/j.dss.2010.07.009

[28] P. Ifinedo, "Understanding information systems security policy compliance: An integration of the theory of planned behavior and the protection motivation theory," Computers \& Security, vol. 31, no. 1, pp. 83-95, 2012. https://doi.org/10.1016/j.cose.2011.10.007

[29] I. Woon, G.-W. Tan, and R. Low, "A protection motivation theory approach to home wireless security," ICIS 2005 proceedings, p. 31, 2005.

[30] D. Gefen, D. Straub, and M.-C. Boudreau, "Structural equation modeling and regression: Guidelines for research practice," Communications of the association for information systems, vol. 4, no. 1, p. 7, 2000. https://doi.org/10.17705/1 cais.00407

[31] M. Abud, "Indonesia: New digital nation," Internews Center for Innovation and Learning, 2012.

[32] J. F. Hair, Multivariate data analysis. Pearson Education India, 2006.

[33] J. Kim and S. Forsythe, "Adoption of virtual try-on technology for online apparel shopping," Journal of Interactive Marketing, vol. 22, no. 2, pp. 45-59, 2008. https://doi.org/ $10.1002 /$ dir. 20113

[34] S. Perez-Lloret et al., "A multi-step pathway connecting short sleep duration to daytime somnolence, reduced attention, and poor academic performance: an exploratory crosssectional study in teenagers," Journal of Clinical Sleep Medicine, vol. 9, no. 05, pp. 469473, 2013. https://doi.org/10.5664/jcsm.2668

[35] J. Chin, B. Jiang, I. Mufidah, S. Persada, and B. Noer, "The Investigation of Consumers' Behavior Intention in Using Green Skincare Products: A Pro-Environmental Behavior Model Approach," Sustainability, vol. 10, no. 11, p. 3922, 2018. https://doi.org/10.3390/su $\underline{10113922}$

[36] I. Mufidah, B. Jiang, S.-C. Lin, J. Chin, Y. Rachmaniati, and S. Persada, "Understanding the Consumers' Behavior Intention in Using Green Ecolabel Product through ProEnvironmental Planned Behavior Model in Developing and Developed Regions: Lessons Learned from Taiwan and Indonesia," Sustainability, vol. 10, no. 5, p. 1423, 2018. https:// doi.org/10.3390/su10051423

[37] Y. T. Prasetyo, A. Suzianti, and A. P. Dewi, "Consumer Preference Analysis on Flute Attributes in Indonesia using Conjoint Analysis," Proceedings of the International Conference on Advanced Design Research and Education (ICADRE14), 2014. https:// doi.org/10.3850/978-981-09-1348-9 038

[38] C. J. Lin and Y. T. Prasetyo, "A metaheuristic-based approach to optimizing color design for military camouflage using particle swarm optimization," Color Research \& Application, 2019. https://doi.org/10.1002/col.22404

[39] C. J. Lin, Y. T. Prasetyo, N. D. Siswanto, and B. C. Jiang, "Optimization of color design for military camouflage in CIELAB color space," Color Research \& Application, vol. 44, no. 3, pp. 367-380, 2019. https://doi.org/10.1002/col.22352

[40] C. J. Lin, Y. T. Prasetyo, and R. Widyaningrum, "Eye movement parameters for performance evaluation in projection-based stereoscopic display, " Journal of Eye Movement Research, vol. 11, no.6, 2018.

[41] C. D. Melas, L. A. Zampetakis, A. Dimopoulou, and V. Moustakis, "Modeling the acceptance of clinical information systems among hospital medical staff: an extended TAM 
model," Journal of biomedical informatics, vol. 44, no. 4, pp. 553-564, 2011. https:// doi.org/10.1016/j.jbi.2011.01.009

[42] B. B. Stern, M. B. Royne, T. F. Stafford, and C. C. Bienstock, "Consumer acceptance of online auctions: An extension and revision of the TAM," Psychology \& Marketing, vol. 25, no. 7, pp. 619-636, 2008. https://doi.org/10.1002/mar.20228

\section{$7 \quad$ Authors}

Bobby Ardiansyah Miraja (Bobby) is currently studying business management for a bachelor degree in the Department of Business Management, Institut Teknologi Sepuluh Nopember (ITS). Bobby's main research interest is in the technology and human resources area.

Satria Fadil Persada, Ph.D (Satria) research interest is studying the behavior of person's in the perspective of consumers and organization. Satria' research interest is also related to pro-environmental behavior.

Yogi Tri Prasetyo, Ph.D (Yogi) is currently an associate professor in School of Industrial Engineering and Engineering Management, Mapua University, Philippines. Dr.Yogi has a wide range of research interest, including applied structural equation modeling in virtual reality, color optimization, human-computer interaction, accident analysis, and usability.

Prawira Fajarindra Belgiawan, P.D research interest is in studying whether people's decision can actually be influenced by their significant others. Fajar's other research interest is in digital disruption.

A.A.N.P Redi, Ph.D research interest is in the field of industrial management.

Article submitted 2019-06-02. Resubmitted 2019-07-26. Final acceptance 2019-07-27. Final version published as submitted by the authors. 